\title{
The Effect of Homelessness on the HIV Care Continuum in an Underserved Metropolitan Area of the South : Potential Implications for Ending the HIV Epidemic in America.
}

Vladimir Berthaud ( $\nabla$ vberthaud@mmc.edu )

Meharry Medical College https://orcid.org/0000-0001-5585-4853

Livette Johnson

Meharry Medical College

Ronda Jennings

Meharry Medical College

Maxine Chandler-Auguste

Meharry Medical College

Abosede Osijo

Meharry Medical College

Marie Baldwin

Meharry Medical College

Paul Juarez

Meharry Medical College

Patricia Matthews-Juarez

Meharry Medical College

Derek Wilus

Meharry Medical College

Mohammad Tabatabai

Meharry Medical College

Research article

Keywords: Homelessness, HIV, social determinants, and viral suppression

Posted Date: December 2nd, 2020

DOl: https://doi.org/10.21203/rs.3.rs-116778/v1

License: (a) This work is licensed under a Creative Commons Attribution 4.0 International License.

Read Full License 
Page 2/24 


\section{Abstract}

A wealth of scientific evidence supports the effectiveness of HIV prophylaxis and treatment. Homelessness has become one of the strongest predictors of health status and viral suppression among vulnerable populations and can undermine the national plan to eliminate HIV by 2030. This retrospective observational study examined the extent in which homelessness affects HIV treatment in an underserved urban area of Middle Tennessee in 2014-2019. Among 692 HIV-seropositive patients, the proportion of homeless patients increased from $13.5 \%$ to $27.7 \%$, thrice the national average for HIV-seropositive people (8.4\%) and twice that of Ryan White patients nationwide (12.9\%). Our findings suggest that homeless patients were half as likely to achieve viral suppression as compared to those who had a permanent/stable home [OR $0.48(0.32-0.72), p$-value $<0.001]$. The alarming rate of homelessness in this population raises serious concerns for long-term HIV treatment outcomes and the trajectory of the syndemic of homelessness and HIV.

\section{Background}

HIV has become a chronic condition, easily manageable by taking one multi-drug, single daily pill. However, the HIV epidemic continues to affect predominantly minorities of color, vulnerable and marginalized populations including homeless persons. The CDC estimates that 1.2 million people aged 13 and older were living with HIV in the United States and 37,832 persons were newly diagnosed HIVseropositive in $2018^{1}$. Of them, Black/African American represented $42 \%$, while they account for just $13 \%$ of the U.S. population. Overall, the number of new infections remains unacceptably high, especially among men having sex with men (MSM) in the age group 25-34, while there has been a $42 \%$ increase in the incidence rate between the Black/African American and Hispanic/Latinx racial groups.

\section{HIV prophylaxis.}

Overwhelming scientific evidence supports the unequivocal effectiveness of HIV prophylaxis and antiretroviral treatment (ART). In spite of this, Black/African Americans continue to experience far worse virologic outcomes, more severe comorbidities, and higher mortality, as compared to other races. Studies have shown that effective antiretroviral therapy leads to sustained virologic suppression and prevents HIV transmission. For example, HPTN-052, an international, multicenter, randomized controlled study showed that early ART defined as initiating ART when CD 4 cell count is 350 to 550 cells $/ \mathrm{mm}^{3}$, was associated with a 93\% lower risk of linked partner infection than was delayed ART (hazard ratio, 0.07; $95 \% \mathrm{Cl}, 0.02$ to 0.22 ). When the index participant had sustained HIV-1 viral suppression, no linked infections were recorded ${ }^{2}$. In conclusion, HPTN 052 provides clear and compelling evidence that treating index participants with CD 4 count between 350 and 550 cells/ $\mu \mathrm{L}$ is beneficial. Anglemyer A. et al. performed a Cochrane Systematic Review of 87 randomized controlled trials, cohort studies and casecontrol studies in $2013^{3}$. They found that in discordant couples, ART was associated with a decreased risk of transmission of HIV. Other data that bear on the benefit of therapy derived from sexual 
partnerships where the index participants had $<350 \mathrm{CD} 4$ cells/ $\mu \mathrm{L}$, but unmeasured confounders remain a significant issue in these cohort studies. The prospective, observational PARTNER (Partners of People on ART-A New Evaluation of the Risks) study was conducted at 75 clinical sites in 14 European countries. It enrolled 1,166 HIV serodifferent couples (HIV-positive partner taking suppressive ART) who reported condomless sex (September 2010 to May 2014). The study population included 548 heterosexual $(61.7 \%)$ and 340 MSM (38.3\%). Eligibility criteria for inclusion of couples' years of follow-up were condomless sex and plasma viral load less than $200 \mathrm{copies} / \mathrm{mL}$. In the preliminary results, among serodifferent heterosexual and same-sex couples in which the HIV-positive partner was using suppressive ART and who reported condomless sex, there were no documented cases of within-couple HIV transmission during median follow-up of 1.3 years per couple (upper 95\%confidence limit, 0.30/100 couples' years of follow-up) ${ }^{4}$. For same-sex couples, the final results of the PARTNER study provide a similar level of evidence on viral suppression and HIV transmission risk as previously reported for heterosexual couples. These findings suggest that the risk of HIV transmission is indeed zero in same-sex couples through condomless sex when the HIV-seropositive partner maintains HIV viral load suppression 5 .

The more recent implementation of pre-exposure and post-exposure HIV prophylaxis (PrEP and PEP) in standard practice has expanded HIV prevention tools for heterosexual and same-sex partners. Large randomized controlled international clinical trials have established the substantive efficacy of PrEP at preventing infection in high-risk heterosexual men and women, as well as MSM. A randomized, doubleblind, placebo-controlled trial enrolled 4,410 HIV-1 partners of heterosexual serodifferent couples in Kenya and Uganda in a three-arm study of daily oral intervention including tenofovir and tenofovir/emtricitabine. The combined results showed that adherence as measured by detection of tenofovir in plasma samples was associated with an $85 \%$ relative risk reduction in HIV-1 transmission for the tenofovir arm and $93 \%$ for the tenofovir/emtricitabine arm $(p<0.001)^{8,9}$. Based on the model proposed in the Preexposure Prophylaxis Initiative (iPrEx) study of 2,499 MSM couples, two doses of tenofovir disoproxil fumarate plus emtricitabine per week correspond to $76 \%$ protection and 4 doses per week to $96 \%$ protection against HIV infection.

The drastic reduction of vertical transmission also illustrates this principle. As the result of scaled up prevention of maternal-to-child transmission interventions, the United States has prevented an estimated $21,956$ (95\% Cl: $20,191-23,759)$ cases of vertical transmissions since $1994^{6}$. As a further attestation of this remarkable scientific achievement, the CDC reported only 73 children under the age of 13 with a diagnosis of perinatally acquired HIV in the United States and dependent areas in $2017^{7}$.

\section{"Ending the HIV Epidemic: A Plan for America” and The National HIV/AIDS Strategy.}

Given the powerful armamentarium at our disposal, elimination of the HIV epidemic is within the reach of our generation. In light of the scientific advances in HIV prevention, care and treatment, the United States 
government has developed the "Ending the HIV Epidemic: A Plan for America," spearheaded by the White House and aiming "to achieve the important goal of reducing new HIV infections to less than 3,000 per year by 2030." Started in 2020, the initial phase targets localities with the highest incidence of HIV transmission. The Plan for America promotes and implements four pillars to reduce HIV transmissions substantially: Diagnose, Treat, Prevent, and Respond ${ }^{10}$. However, the Plan for America does not specifically address social determinants of health.

From another perspective, the 5-year plan of the National HIV/AIDS Strategy 2020 focuses on four overarching goals: reduce new HIV infections; increase access to care and improve health outcomes for PLWH; reduce HIV-related health disparities and health inequities; and achieve a more coordinated national response ${ }^{11}$. The HIV care continuum illustrates program performance at different stages that include HIV diagnosis, linkage to care, retention in care, and viral suppression, the key performance measure ${ }^{12}$. Incomplete viral suppression could increase the risk of HIV transmission and jeopardize "Ending the HIV Epidemic: A Plan for America." Homelessness may erode outcome performance throughout the four stages of HIV care and hinder the four goals of the National HIV/AIDS Strategy in underserved communities.

\section{Homelessness and health outcomes.}

The scientific literature offers high-level evidence of a strong relationship between homelessness and viral suppression. Investigators of the Women's Interagency HIV Study (WIHS) evaluated the effect of unstable housing on viral suppression (viral load $<200$ copies $/ \mathrm{mL}$ ) and CD4 cell count in 3,082 participants in Chicago, Los Angeles, San Francisco, Brooklyn, Bronx, and Washington, DC, between 1995 and 2015. Using an extended probit model with the allocations for the Housing Opportunities for People with AIDS (HOPWA) per newly HIV-seropositive individual as the instrument variable, they found that unstable housing reduces the likelihood of viral suppression by $51 \%$ and the probability of achieving adequate CD 4 cell count by $53 \%{ }^{13}$. Nationwide, Ryan White clients with temporary or unstable housing continue to have the lowest percentages of viral suppression, although percentages are steadily increasing. Among temporarily housed clients, viral suppression increased from $63.7 \%$ in 2010 to $80.7 \%$ in 2018. Among unstably housed clients, viral suppression increased from $54.8 \%$ in 2010 to $72.4 \%$ in 2018. Comparatively, viral suppression among clients with stable housing increased from $71.2 \%$ in 2010 to $88.4 \%$ in $2018^{14}$. We reiterate that incomplete viral suppression could increase the risk of HIV transmission and jeopardize "Ending the HIV Epidemic: A Plan for America" and the National HIV/AIDS Strategy. In the United States, according to US Department of Housing and Urban Development, 552,830 people experienced homelessness in a single night in January 2018 and 40\% of them were Black or African American ${ }^{15}$.

Moreover, HIV-seropositive persons are disproportionately overrepresented among the homeless population. While the homeless population continues to grow exponentially, the National Alliance to End Homelessness estimated that HIV-seropositive persons made up $3.4 \%$ of homeless population in the 
United States in 2007, while they represented $0.4 \%$ of the general population. Later, in 2016, the CDC reported that $8.4 \%$ of people in HIV medical care were homeless ${ }^{16}$. To examine the effect of housing status on different health outcomes, Chad Leaver and his group undertook a systematic review of 29 studies. Their results suggest that housing instability represents a strong predictor of non-adherence to antiretroviral therapy, HIV risk behaviors, utilization of health and social services, and health status ${ }^{17}$. A second systematic review of 152 studies involving 139,757 participants found substantial evidence that inadequate housing represents a significant barrier to reduction of HIV risk behaviors, access to HIV medical care, treatment adherence, and sustained viral suppression ${ }^{18}$. A third qualitative review of 17 published papers examining the effect of homelessness on health status, HIV treatment adherence, and health outcomes showed that homelessness is highly prevalent among PLWHA and strongly associated with poorer health status, lower adherence to antiretroviral therapy, and worse CD 4 cell count and viral load outcomes ${ }^{19}$.

\section{Homelessness in Nashville, Tennessee.}

During the past five years, in Nashville, Tennessee, the trend of homelessness paralleled the economic growth curve that propelled a booming housing market and aggressive gentrification. Nashville officials located approximately 2,300 homeless people on an overnight count in 2017. However, local advocates estimate the number of people in Nashville living on the streets, in cars, camps, motels or in shelters at $20,000^{20}$. As one of the fastest growing cities in the United States, Nashville reported 30,000 new residents in 2018 , while average rents increased from $\$ 882$ in 2013 to $\$ 1,428$ today citywide in 2018 . One year later, in the aftermath of the March 3, 2020 devastating tornado and the ongoing coronavirus pandemic, the number of homeless in Nashville is certainly much higher. The majority of the patients attending Meharry Community Wellness Center (MCWC) resides in North Nashville, an area directly hit by the tornado. Subsequently, many of them lost their jobs in places such as hotels, restaurants, and factories due to local and state government-imposed "Stay-at-Home" and social distancing orders related to mitigation of the COVID-19 pandemic. The national economic downturn could exacerbate the homelessness crisis in the United States and widen the gaps in care and HIV health disparities.

\section{Methods}

\section{Study setting.}

Meharry Medical College is located at the epicenter of the HIV epidemic in North Nashville, Davidson County, in Middle Tennessee. Thirteen counties including Davidson make the Nashville Transitional Grant Area (TGA) of the Ryan White Part A program. While about 39\% of the TGA's population lives in Davidson County, $76.5 \%$ of the PLWH population resides in Davidson County. Twenty percent of them had been in jail, $42 \%$ homeless/unstably housed at some point in the last year, while $40.2 \%$ did not have food to eat three or more days at some point in the last year, according to Nashville Metro Health Department statistics. As a Tennessee-designated AIDS Center of Excellence, Meharry Community Wellness Center 
(MCWC) has been a major provider of comprehensive, integrated, and patient-centered care and health services for the most vulnerable PLWH in Davidson County since 2005.

\section{Study design.}

We conducted a retrospective analysis of 692 HIV-seropositive adult and adolescent patients seen at MCWC between 2014 and 2019. The Meharry Institutional Review Board (IRB) had approved this study.

Inclusion criteria. All adult and adolescent patients who had at least one medical visit at MCWC between January 1, 2014 and December 31, 2019 were included. This analysis accounts for all patients who expired during the study period.

Exclusion criteria. From this study analysis, we excluded prison inmates of Tennessee Department of Corrections, seen through our telemedicine program and jail inmates who had face-to-face clinic encounters.

Data sources. Data elements extracted from CAREWare electronic patients' charts included the following: age group, race/ethnicity, gender, HIV risk factor, federal poverty level (FPL), type of medical insurance, housing status, rate of clinic visits per month, last recorded CD4 cell count and plasma HIV viral load. MCWC staff entered all data elements in CAREWare at each patient visit. We performed data quality check, for accuracy, duplication, missing, and unknown elements before generating the study database. No personal identifiers were included. Nearly all viral load and CD 4 cell count results were imported from our contractual commercial lab web portal and very few of them came from external providers' reports.

\section{Measures.}

Primary outcome variable. Viral load suppression, defined as plasma HIV viral load below the detection limit of 20 copies/mL measured by Real Time PCR assay, constituted the primary outcome variable. Of note, our viral suppression threshold is lower than commonly used $200 \mathrm{copies} / \mathrm{mL}$ in published reports.

Predictive variables. We chose a pool of predictive variables from patient's electronic medical records (CAREWare 6, version 58). Demographic variables consisted of age group (18-24, 25-44, 45-64, and 65+), gender (male, female and transgender), and race/ethnicity (Black or African American, non-Hispanic white, and other including Hispanic/Latinx). Variables of social determinants of health comprise HIV risk category (heterosexual, MSM, and/or bisexual men, injection drug use or IDU, and other), housing status (permanently housed and homeless), FPL, and type of medical insurance (no insurance, Medicaid/Medicare, private insurance and other). The homeless category consisted of patients living in the streets, shelters, transition homes, and those in temporary residence. We did not use the classification of stable/unstable housing. We entered modified adjusted gross income (MAGI) as the percentage of FPL, computed automatically by CAREWare, and we analyzed it as a continuous variable. As a payor of last resort, the Ryan White Program provided ambulatory/outpatient medical insurance coverage to 
eligible, low-income, uninsured clients. We determined retention in care as the rate of monthly medical visits. The last recorded CD 4 cell count and plasma viral load were collected for this study. We treated CD4 cell count and viral load as dichotomous variables ( $<500$ or $\geq 500$ cells $\left./ \mathrm{mm}^{3}\right)$ and $(\leq 20$ or $>20$ copies $/ \mathrm{mL}$ ). We considered plasma viral load $\leq 20$ copies $/ \mathrm{mL}$ as viral suppression.

\section{Statistical analysis.}

First, we performed exploratory data analysis and checked for data quality, distribution, and assumption violations. We applied Pearson's $\chi 2$ test to determine the association between pairs of categorical variables. Then, we used a multivariable logistic regression to find out the effect of homelessness on viral load suppression, controlling for demographic, social, and clinical variables: age group, gender, race/ethnicity, type of medical insurance, FPL, HIV risk factor, rate of outpatient and HRSA visits, and CD4 cell count. Finally, we plotted a receiver operating characteristic (ROC) curve to corroborate the result.

\section{Results}

\section{Population characteristics.}

Table 1 summarizes the main characteristics of study population. From 2014 to 2019, this study enrolled 692 HIV-seropositive patients, 498 males (72\%), 184 females (26.6\%), and 10 transgender (1.4\%). The majority of the patients (79.6\%) were Black/African American, $15 \%$ were non-Hispanic White, and $5.3 \%$ belonged to another race category, almost all of them identified as Hispanic/Latinx. Youth (age 18-24 years) accounted for $5.8 \%$, while the age groups $25-44,45-64$, and $65+$ years represented $41.5 \%, 46.5 \%$, and $6.2 \%$ of the study population respectively. Most of the patients $(69.1 \%$ in 2014 and $60.5 \%$ in 2019$)$ lived below $100 \%$ of the FPL. The hallmark of our patient population was the alarming number of homeless: 192. In fact, this number increased three-fold higher than the national average for HIVseropositive people (8.4\%) ${ }^{16}$ and twice the average proportion of homeless Ryan White patients nationwide $(12.9 \%)^{21}$. In the aftermath of the devastating tornado of March 3, 2020 and the ongoing COVID-19 pandemic, the proportion of homeless may skyrocket in year 2020 and beyond. As a payor of last resort, the Ryan White program covered all eligible, low-income, uninsured patients, under either Part B-subsidized Insurance Assistance Program (IAP), or Ryan White Part A Transitional Grant Area or C Early Intervention Services. Thus, the Ryan White programs covered 260 patients (37.6\%). Other publicly insured health plans, Medicaid and Medicare, covered $23.1 \%$ and $13.4 \%$, respectively. Fourteen patients (2\%) were inmates of county jails and excluded from the study. The group of privately insured patients (23.8\%) encompassed Affordable Care Act (ACA) customers (14.8\%) and a small number of medically insured clients through employer-sponsored health plans (9\%). In relation to HIV risk factor, $46 \%$ of the patients reported as heterosexual in 2019 , a sharp decrease from $62.4 \%$ in 2014 , partly attributed to the proportional increase in MSM, from $34.8 \%$ in 2014 to $42.8 \%$ in 2019. This reflects the current epidemic trend in the South. The proportion of patients who considered IDU as their HIV risk category decreased from $11.4 \%$ in 2014 to $9.4 \%$ in 2019 , reflecting the epidemic shift in opioid addiction, from inner cities to 
suburban and rural areas, and from Black/African American to White/Caucasian communities. This observation correlates with the overall decrease in the number of clients tested with chronic hepatitis $\mathrm{C}$ infection from $74 \%$ in 2014 to $57 \%$ in 2019 . 
Table 1

Descriptive characteristics and bivariate chi-square odds ratio of HIV-positive patients by housing status

\begin{tabular}{|c|c|c|c|c|c|}
\hline & Total & Permanently Housed & Homeless & p-value & $\begin{array}{l}\text { Odds Ratio } \\
95 \% \mathrm{Cl}\end{array}$ \\
\hline Unweighted N & 692 & 500 & 192 & & \\
\hline Gender & & & & 0.514 & \\
\hline Male & 498 & $70.8 \%$ & $75 \%$ & & $1.33(0.27,6.51)$ \\
\hline Female & 184 & $27.6 \%$ & $24 \%$ & & $1.627(0.34,7.6)$ \\
\hline Transgender & 10 & $1.6 \%$ & $1 \%$ & & (Ref) \\
\hline Race/ethnicity & & & & 0.119 & \\
\hline Black & 551 & $79.2 \%$ & $80.7 \%$ & & $2.51(0.96,6.55)$ \\
\hline White/non-Hispanic & 104 & $14.4 \%$ & $16.7 \%$ & & $2.84(1.02,7.97)$ \\
\hline Other & 37 & & & & (Ref) \\
\hline Age Group & & & & 0.025 & \\
\hline $18-24$ & 40 & $5.2 \%$ & $7.3 \%$ & & $5.25(1.56,17.73)$ \\
\hline $25-44$ & 287 & $42 \%$ & $41 \%$ & & $3.58(1.24,10.34)$ \\
\hline $45-64$ & 322 & $45 \%$ & $50.5 \%$ & & $4.20(1.46,12.09)$ \\
\hline $65+$ & 43 & $7.8 \%$ & $2.1 \%$ & & \\
\hline HIV Risk Factor & & & & 0.085 & \\
\hline Heterosexual & 318 & $45.4 \%$ & $47.4 \%$ & & $0.80(.072,8.95)$ \\
\hline IDU & 65 & $8.8 \%$ & $10.9 \%$ & & $0.96(0.08,11.13)$ \\
\hline MSM & 296 & $44.6 \%$ & $38 \%$ & & $0.66(0.06,7.33)$ \\
\hline Other & 13 & $1.2 \%$ & $3.6 \%$ & & (Ref) \\
\hline Insurance Type & & & & $<0.001$ & \\
\hline Medicaid & 160 & $22 \%$ & $26 \%$ & & $2.81(1.61,4.88)$ \\
\hline Medicare & 93 & $15 \%$ & $9.4 \%$ & & $1.48(0.75,2.92)$ \\
\hline Ryan White & 260 & $32 \%$ & $52.1 \%$ & & $3.86(2.33,6.40)$ \\
\hline Corrections & 14 & $3.1 \%$ & & & $0.48(0.06,3.81)$ \\
\hline Private & 165 & $28.4 \%$ & $12 \%$ & & (Ref) \\
\hline
\end{tabular}




\begin{tabular}{|llllll|}
\hline$<500$ & 315 & $42.6 \%$ & $53.1 \%$ & $1.527(1.09,2.13)$ \\
\hline $\mathbf{5 0 0}$ & 377 & $57.4 \%$ & $46.9 \%$ & (Ref) \\
\hline HIV Viral Load & & & & & \\
\hline Suppressed & 477 & $78 \%$ & $22 \%$ & $<0.001$ & $2.41(1.70,3.41)$ \\
\hline Not Suppressed & 215 & $25.6 \%$ & $45.3 \%$ & (Ref) & (Ref) \\
\hline
\end{tabular}

\section{Essential clinical outcomes.}

Testing for the essential biologic markers of antiretroviral treatment revealed that $54.5 \%$ of the patients had a robust CD 4 cell count $\geq 500$ cells $/ \mathrm{mm}^{3}$ (HIV infection, stage 1 ) and $68.9 \%$ of them achieved plasma viral load suppression below the detection limit of $20 \mathrm{copies} / \mathrm{mL}$. Permanently housed patients had a much higher proportion of viral suppression compared with their homeless counterparts. Among patients with viral load less than 20 copies $/ \mathrm{mL}, 78 \%$ were permanently/stably housed and $22 \%$ were homeless, while $74 \%$ of permanently/housed patients reached viral suppression and a much smaller proportion of the homeless patients $(54.7 \%)$ remained virally suppressed (Pearson's Chi-Square 25.171, $p<0.001$ ).

The multivariable logistic regression demonstrated that permanent/stable housing ( $p$-value $<0.001$ ) was a strong predictor of plasma HIV viral load suppression. It also revealed that higher frequency of CD4 cell count $\geq 500$ cells $/ \mathrm{mm}^{3}$ (HIV infection, stage 1$)$ (p-value $\left.<0.001\right)$ were also strong predictors of viral load suppression. The remaining logistic model variables were the following: age ( $p$-value $=0.004), F P L(p-$ value $=0.031)$, gender $(p$-value $=0.328)$, race/ethnicity $(p$-value $=0.605)$, HIV risk factor $(p$-value $=0.659)$, and type of medical insurance ( $p$-value $=0.791$ ). The FPL had a mean of 100.9 and standard deviation of 129.5, while $60.5 \%$ of the clients had an annual income under $100 \%$ of FPL. As expected, patients living in permanent/stable housing had twice the chance of achieving viral suppression compared with those who were homeless [OR 2.08 (1.39-3.23), p-value $<0.001$ ]. The CD4 count cut-off of 500 cells $/ \mathrm{mm}^{3}$ was indeed representative of our patient population since $88.2 \%$ of them had CD4 count greater than $200 \mathrm{cells} / \mathrm{mm}^{3}$. Under the nonparametric assumption, the receiver operating characteristic (ROC) curve plotted in figure 1 correctly predicted $72.3 \%$ of the primary outcome variable, plasma HIV viral load suppression (AUC = 0.767 ; p-value $<0.001 ; 95 \% \mathrm{Cl}$ for AUC $(0.73,0.80)$.

During the five-year study period, 52 patients died. Of them, 16 (30.76\%) were homeless and $36(69.23 \%)$ lived in stable housing, while $12.5 \%$ of the homeless and $61.12 \%$ of those in stable housing achieved viral suppression at the time of death.

\section{Discussion}

\section{Impact of homelessness on viral suppression.}


This retrospective cohort analysis underscores the drastic spike of homelessness among Black/African American PLWHA in Nashville, Tennessee during the past five years. The findings indicate that homelessness, lower retention in care and CD4 cell count less than 500 cells $/ \mathrm{mm}^{3}$ may be associated with sub-optimal viral suppression. Investigators in San Francisco drew similar conclusions from a surveillance study of 862 residents aged 13 years or over, diagnosed with HIV/AIDS between January 1 , 2009 and December 31, 2010. The multivariable model showed that homelessness was an independent predictor of virologic failure (plasma viral load $>200 \mathrm{copies} / \mathrm{mL}$ ). So were having a single (OR $11.50,95 \%$ $\mathrm{Cl} 7.8-17.1$ ), or two medical visits (OR 3.21, 95\% Cl 2.0-5.1) compared to three visits within 12 months after diagnosis, and age $<40$ years $(\mathrm{OR} 1.92,95 \% \mathrm{Cl} 1.4-2.7)^{22}$. Contrary to most other publications, gender, race, FPL, and type of medical insurance did not predict viral load suppression. A possible explanation to this observation stems from the overrepresentation of Black/African Americans, high prevalence of poverty, and universal medical insurance coverage through Ryan White Program in our cohort of participants. In general, women and older individuals have better rates of viral suppression as compared with men and youth. A smaller study including 95 homeless PLWHA for whom viral load information was available found an odds ratio of incomplete viral suppression (plasma viral load $>75$ copies $\left./ \mathrm{mm}^{3}\right) 3.84$ times higher in homeless compared with housed persons $(95 \% \mathrm{Cl} 1.36-10.36)^{23}$. A team of investigators in Canada conducted a sub-study using data from their AIDS Care Cohort to evaluate Exposure to Survival Services (ACCESS) in order to examine the relationship between the duration of homelessness and the likelihood of plasma viral suppression among a cohort of $922 \mathrm{HIV}$ seropositive persons who use drugs between May 1996 and June 2014. After adjusting for potential confounders, they found that longer duration of homelessness was associated with lower odds of viral suppression (adjusted odds ratio $=0.71$ per six-month period of homelessness, $95 \% \mathrm{Cl} 0.60-0.83)^{24}$. Researchers in San Francisco analyzed the granular impact of various degrees of housing instability through six different living arrangements of 1,222 HIV-seropositive patients from February to July 2017. They discovered a "dose-response" relationship between greater housing instability and lower rates of virologic suppression, ranging from $42 \%$ (living outdoors) to $85 \%$ (rent/own dwelling). Moreover, they found that being African American was associated with lower rates of viral suppression compared with being White, even after adjusting for housing status (OR: $0.67,95 \% \mathrm{Cl} 0.46-0.99$ ); $\mathrm{P}=0.044)^{25}$. In a crosssectional, behavioral survey of 7,925 adults including 304 homeless deriving from the CDC HIV/AIDS Surveillance Project, which took place across 19 sites throughout the United States between May 2000 and December 2003, investigators examined the effect of homelessness on health outcomes. They observed that PLWHA experiencing homelessness had lower adherence to antiretroviral treatment, lower CD 4 cell count, lower likelihood of viral suppression (plasma viral load $<500$ copies $/ \mathrm{mL}$ ), and higher rates of negative health outcomes ${ }^{26}$. Another multisite study evaluated the effect of unstable housing on viral suppression (plasma viral load $<200$ copies $/ \mathrm{mL}$ ) and adequate CD4 cell count (CD $4>350$ cells $/ \mu \mathrm{L}$ ) using an extended probit model with the instrumental variable measuring housing allocation among 3,082 participants of the WIHS at sites in New York, Chicago, Washington, DC, and Los Angeles. The study results showed that unstable housing reduced the probability of viral suppression and adequate CD 4 cell count by $51 \%$ and $53 \%$ respectively ${ }^{13}$. In fact, supportive housing program such as Shelter Plus 
Care, in Cincinnati, Ohio, which enrolled 86 participants between 2008 and 2016 had achieved statistically significant improvements on CD4 cell count $\left(>500\right.$ cells $\left./ \mathrm{mm}^{3}\right)$ and viral suppression (plasma viral load $<200$ copies/mL), $45 \%$ and $79 \%$ respectively 27 .

\section{Impact of incarceration on viral suppression.}

Many studies have shown that incarceration is associated with poor health outcomes among HIVseropositive adults including greater use of emergency room visits and hospital admissions, and lower prevalence of viral suppression ${ }^{28,29}$. According to the Brookings Institution, North Nashville has an incarceration rate of $14 \%$, the highest in the country by far, and $93 \%$ of those incarcerated are Blacks. In other words, one in seven people who were born in the primary zip code of North Nashville between 1980 and 1986 went to jail or prison at some point in their lives ${ }^{30}$. Twenty five percent of our patients reside in that neighborhood and $41 \%$ of them belong to this age group. The surge in unemployment related to the COVID-19 pandemic exacerbates homelessness, depression/anxiety, and drug use and could fuel the cycle of poverty, incarceration and recidivism. These poor outcomes not only impose a financial burden on the strained healthcare system but also magnify the risk of HIV transmission and jeopardize the plan to end the HIV epidemic and HIV disparities.

\section{Impact of homelessness on mortality.}

Homelessness affects not only viral suppression but also the survival of PLWHA and the occurrence of cardiovascular comorbidity and mortality. In a large study of all-cause mortality among 6,558 people living with AIDS in San Francisco, including 641 homeless, $67 \%$ of the homeless persons survived five years compared with $81 \%$ of their housed counterparts $(p<0.0001)$. After adjustments for potential confounders, the adjusted relative hazard (aRH) for homelessness was 1.20 (95\% Cl 1.03-1.41).

Supportive housing lowered the risk of death (aRH $0.20(95 \% \mathrm{Cl} 0.05-0.81))^{31}$. A two-year observational study conducted in New York City underlines the significant role of temporary pattern of homelessness and sporadic incarceration on higher mortality risk from all-cause, drug-related, and HIV as compared with continuous homelessness and persistent incarceration ${ }^{32}$. Homelessness and incarceration may accelerate HIV disease progression and mortality. A longitudinal study assessing differences in causes of death among housed and homeless people diagnosed with HIV in San Francisco revealed that at the time of death, homeless HIV-seropositive persons tend to be younger, the proportion of AIDS-related mortality tend to decrease, while heart disease and mental disorders are emerging causes of death ${ }^{33}$.

\section{Potential impact of the COVID-19 pandemic on homelessness in Nashville.}


The U.S. Department of Housing and Urban Development estimated that 1.4 million persons access transitional housing or emergency shelters each year ${ }^{34}$. These congregated settings pose high risk for transmission of SARS-COV-2 infection, as reported in cities such as Nashville where 100 out of 374 residents tested positive for COVID-19 ${ }^{35}$. The CDC found high proportions of residents and staff members of 19 homeless shelters who tested positive for COVID-19 in Seattle (17\% of residents; $17 \%$ of staff members), Boston $(36 \% ; 30 \%)$, and San Francisco $(66 \% ; 16 \%)^{36}$. So far, it does not appear that PLWHA and on effective antiretroviral treatment are at increased risk of coronavirus infection and severe disease. However, African Americans and Latinx are certainly at a much higher risk for coronavirus disease severity and mortality, as already reported in New York, Michigan, and elsewhere ${ }^{37,38,39}$. Furthermore, the SARS-Coronavirus-2019 pandemic may represent the greatest danger for homeless PLWHA in the United States. Researchers at Boston University estimate that 21,295 people experiencing homelessness, or $4.3 \%$ of the U.S. homeless population, could require hospitalization at the peak infection rate of $40 \%$, with a potential range from $2.4 \%$ to $10.3 \%$ hospitalizations ${ }^{40}$. At Nashville Rescue Mission, 100 residents tested positive for COVID-19 and 274 tested negative. There were 19 positive cases reported at The Tennessee State Fairgrounds, currently used as a homeless overflow shelter, with 206 testing negative ${ }^{41}$. The degree of COVID-19 impact in Nashville could vary between moderate and severe. A team of economists from Harvard and Brown Universities developed a special platform to track economic activity in real time and measure the impact of the COVID-19 crisis at a granular level. As a harbinger of the grim economic forecast in Nashville, total consumer spending decreased by $46.3 \%$, more than twice the United States' average drop $(20.5 \%)^{42}$.

\section{Summary.}

In spite of the different viral suppression thresholds and homelessness nomenclature used, all published studies concur that homelessness is associated with lower prevalence of viral suppression in PLWHA and many of them show a trend in overall worse health outcomes. Several randomized controlled trials have demonstrated substantial benefits of housing interventions on viral suppression, morbidity, and mortality. We need to mobilize our resources and create innovative programs that respond to the needs of homeless PLWHA in the era of social distancing related to the COVID-19 pandemic.

\section{Strengths and Limitations.}

Strengths of our study include use of a population disproportionately affected by homelessness and HIV/AIDS, adequate sample size and follow-up duration, and collection of data using validated measures.

Nonetheless, this retrospective study has several limitations. First, it does not clearly establish homelessness as an independent predictor of virologic failure because the study did not address other well-known predictive variables (mental health, substance use disorders, health literacy/numeracy, etc.) in the multivariable logistic regression. Nonetheless, a theoretical mathematical model analyzing the effect 
of homelessness on HIV/AIDS transmission dynamics and comparing housing status-induced reproduction numbers suggests that lack of entertainment, poor nutrition, and co-infection with other sexually transmitted infections in homeless individuals may enhance HIV transmission and AIDS-related deaths ${ }^{43}$. The Research on Access to Care in the Homeless (REACH) recruited 104 participants from San Francisco homeless shelters, free-meal programs, and single room-occupancy hotels charging less than $\$ 600 /$ month. They discovered that severely food unsecure participants had $>80 \%$ lower likelihood of adherence and $77 \%$ lower odds of viral suppression (viral load $<50$ copies $/ \mathrm{mL}$ ) $(95 \% \mathrm{Cl}: 0.06-0.82)^{44}$. A prospective cohort study of $288 \mathrm{HIV}$-seropositive homeless and unstably housed men, conducted in San Francisco between 2002 and 2008 concluded that the inability to meet food, hygiene, and housing needs was the most powerful predictor of physical and mental health, after adjusting for age, race, income, and CD4 cell count ${ }^{45}$. In the context of the COVID-19 pandemic, rising job and food insecurity raises serious concerns. These factors are important because $30 \%$ of our patients are facing challenging mental health issues and substance use disorders. More than $50 \%$ of our patients did not graduate from high school. The majority of them read at fifth grade level and lack the emotional and familial support to deal with their illnesses in a community with pervasive stigma.

Second, the study cohort does not reflect the racial/ethnic representation of the general population. For example, the proportion of Hispanic/Latinx and transgender communities is relatively small. However, HIV/AIDS and homelessness affect primarily underserved Black/African American communities.

Nevertheless, other studies have shown that housing status could be a stronger predictor of HIV health outcomes than demographic features, mental health, substance use disorders, or utilization of other services.

Third, the study does not account for non-infectious comorbidities that could have contributed to higher rates of hospitalizations and emergency room visits, more frequent drug interactions, intolerance, and side effects, leading to sub-optimal treatment adherence and lower rate of viral load suppression, and higher mortality. These critical issues deserve utmost attention because HIV infection may contribute to chronic, sub-clinical inflammation, which promotes the development of cardiovascular and metabolic complications. Notwithstanding the study limitations, multiple researchers have reported the findings that homelessness may be associated with sub-optimal viral suppression.

\section{Conclusions}

The scientific literature provides substantial evidence of homelessness-related poor health outcomes. Our study has weaknesses inherent in observational data, but we find it reassuring that our results arrive at the consistent message that homelessness contributes to sub-optimal viral suppression in PLWHA. These findings should alert public policy makers on the urgent need to mitigate the deleterious consequences of gentrification and the shortfall of affordable housing on the health outcomes of underserved, low-income HIV-seropositive individuals residing in large metropolitan areas of the United States. Stigmatization and marginalization of homeless individuals and HIV-seropositive persons, implicit bias and discrimination, antiquated housing laws, and unfair criminal justice system deserve renewed attention of federal, state, 
and local authorities. The United States has already missed the CDC goal to reduce the current percentage of persons receiving HIV medical care who are homeless (8.4\%), to no more than $5 \%$ in $2020^{16}$.

The successful implementation of "Ending the HIV Epidemic: A Plan for America" and The National HIV/AIDS Strategy will require a multi-pronged approach to HIV prevention and care, integrated housing services and novel policies and programs. As a public health intervention, housing services align with national medical priorities such as disease prevention and unfettered access to cost-effective and quality health care. In the context of COVID-19 crisis, skyrocketing unemployment, stay-at-home and social distancing measures will likely propel a surge in anxiety/depression, fear of homelessness, substance use, and poorer treatment adherence, leading to virologic failure, increased risk of cardiovascular events, and excess mortality. At the core of the conceptual framework of the syndemic affecting Black/African Americans in Nashville, Tennessee, HIV/AIDS, homelessness, incarceration, socio-economic status, substance use disorder are intertwined and should be addressed collectively. In the context of the COVID19 pandemic, social distancing rules, stay-at-home and shelter-in-place orders bring brand new, dreadful challenges to homeless PLWHA in the streets and shelters. For Black/African Americans, the shocking disparities in COVID-19 exposure, testing, morbidity, and mortality raise urgent medical and social concerns. For Black/African Americans living with HIV/AIDS in Nashville, Tennessee, excess rate of homelessness and incarceration had become major challenges to retention in care and sustained viral suppression. Structural factors such as institutional racism, predatory lending practices, and red lining, limited public transportation and access to digital communication, HIV stigma and discrimination, as well as mental and substance use disorders represent other important challenges.

\section{Abbreviations}

ACA: Affordable Care Act

ACCESS: AIDS Care Cohort to evaluate Exposure to Survival Services

AIDS: Acquired immunodeficiency syndrome

aRH: Adjusted relative hazard

ART: Antiretroviral treatment

AUC: Area under the curve

CD4: CD4 T lymphocytes

CDC: Centers for Disease Control and Prevention

Cl: Confidence interval 
COVID-19: Coronavirus disease 2019

FPL: Federal poverty level

HIV: Human immunodeficiency virus

HOPWA: Housing Opportunities for People with AIDS

HPTN 052: HIV Prevention Trials Network

IAP: Insurance Assistance Program

IDU: Injection drug use

iPrEx: Preexposure Prophylaxis Initiative

IRB: Institutional Review Board

MAGI: Modified adjusted gross income

MCWC: Meharry Community Wellness Center

MSM: Men having sex with men

OR: Odds ratio

PARTNER: Partners of People on ART-A New Evaluation of the Risks

PCR: Polymerase chain reaction

PEP: Post-exposure HIV prophylaxis

PLWHA: Persons living with HIV/AIDS

PLWH: People living with HIV

PrEP: Pre-exposure HIV prophylaxis

REACH: Research on Access to Care in the Homeless

ROC: Receiver operating characteristic

SARS: Severe acute respiratory syndrome

SARS-COV-2: Severe acute respiratory syndrome coronavirus 2

TGA: Nashville Transitional Grant Area 


\section{Declarations}

\section{Ethics approval and consent to participate:}

The Meharry IRB reviewed the study protocol and documents and approved this study. All data collected for the preparation of this manuscript are available in CAREWare and accessible through secured website.

\section{Consent for publish:}

Not applicable.

\section{Availability of data and materials:}

The datasets generated and/or analyzed during the current study are not publicly available due to the confidentiality and sensitive nature of the patients' data but are available from the corresponding author on reasonable request.

\section{Competing interests:}

None of the authors has declared any competing interests.

\section{Funding:}

Dr. Berthaud received primary grant support from Human Resources and Services Administration/HIV/AIDS Bureau, grants U90HA29237, HL6HA01706 and H7CHA36789. Tennessee Health Department AIDS Centers of Excellence and Ryan White Part B grants 34349-90218 and 3434987418 funded part of this project. Metropolitan Nashville Health Department Ryan White Part A also supported this project under grants $357545,357504,357557,357539$, and 357555 . The National Institute of Health/National Institute of Allergy and Infectious Diseases, Tennessee Center for AIDS Research grant P30 Al110527 supported part of this research. Dr. Berthaud also received grant funding from the Department of Housing and Urban Development/Metropolitan Department of Housing Authority and United Way of Middle Tennessee in direct funding for this project. The funders had no role in study design, data collection and analysis, decision to publish, or preparation of the manuscript.

The Meharry Medical College RCMI grant (NIH grant MD007586) supported the following authors: Dr. Tabatabai and Mr. Wilus. HRSA has partially funded this project under grant number UH1HP30348 for the 
following authors: Dr. Matthews-Juarez, Dr. Juarez, and Dr. Tabatabai. This information or content and conclusions are those of the authors. The reader should not construct them as the official position or policy of, nor infer any endorsements by RCMI, NIH, and HOPWA, Tennessee Health Department AIDS Centers of Excellence and Ryan White Part B, Metropolitan Nashville Health Department Ryan White Part A, the National Institute of Health/National Institute of Allergy and Infectious Diseases, or HRSA.

\section{Authors' contributions:}

Dr. Berthaud was responsible for the overall study design, database and manuscript writing. Dr. Tabatabai and Derek Wilus performed the statistical analysis, data interpretation and manuscript editing. The other authors participated in study concept, data collection and manuscript review. Dr. Patricia Matthews-Juarez and Dr. Paul Juarez reviewed the data for scientific content. Dr. Livette Johnson, Maxine Chandler-Auguste, Ronda Jennings, Abosede Osijo, and Marie Baldwin contributed to data collection.

\section{Acknowledgements:}

The authors acknowledge the invaluable contribution of Takizala, Zudi-Mwak, MBA, MD, MPH, for working diligently on the regulatory procedures and submission of the manuscript.

\section{References}

1. Centers for Disease Control and Prevention. Estimated HIV incidence and prevalence in the United States, 2014-2018. HIV Surveillance Report, Supplemental Report, volume 24, Number 1.

2. Cohen MS, Chen YQ, McCauley M, et al. Antiretroviral Therapy for the Prevention of HIV-1 Transmission. N Engl J Med. 2016 September 1; 375(9): 830-839.

3. Anglemyer A, Rutherford GW, Horvath T et al. Antiretroviral therapy for prevention of HIV transmission in HIV discordant couples. Cochrane Database Syst Rev. 2013; 4: CD009153. doi: 10.1002/14651858.CD009153.pub3.

4. Rodger AJ, Cambiano V, Bruun T et al. Sexual activity without condoms and risk of HIV transmission in serodifferent couples when the HIV-positive partner is using suppressive antiretroviral therapy. JAMA 2016; 316(2):171-181.

5. Rodger AJ, Cambiano V, Bruun T et al. Risk of HIV transmission through condomless sex in serodifferent gay couples with the HIV-positive partner taking suppressive antiretroviral therapy (PARTNER): final results of a multicentre, prospective, observational study. Lancet. 2019 Jun 15 ; 393(10189) : 2428-2438.

6. Little KM, Taylor AW, Borkow CB et al. Perinatal Antiretroviral Exposure and Prevented Mother-to-child HIV Infections in the Era of Antiretroviral Prophylaxis in the United States, 1994-2010. Pediatr Infect Dis J. 2017 January; 36(1): 66-71. 
7. Diagnoses of HIV infection in the United States and dependent areas, 2017. HIV Surveillance Report 2018; 29.

8. Anderson PL, Glidden DV, Liu A, et al: Emtricitabine-tenofovir concentrations and pre-exposure prophylaxis efficacy in men who have sex with men. Sci Transl Med 2012; 4 (151): 151 ra125. doi:10.1126/scitransImed.3004006.

9. Baeten JM, Donnell D, Mugo NR et al. Single-agent tenofovir versus combination emtricitabine/tenofovir for pre-exposure prophylaxis against HIV-1 acquisition : a randomized trial. Lancet Infect Dis. 2014 November ; 14(11) : 1055-1064.

10. Statement on FY2020 Budget Proposal for Ending the HIV Epidemic. Ending the HIV Epidemic: A Plan for America. Published March 11, 2019. Accessed May 1, 2020.

https://www.hhs.gov/about/news/2019/03/11/statement-on-fy2020-budget-proposal-for-endingthe-hiv-epidemic-in-america.html- 48k-2019-03-14

11. National HIV/AIDS Strategy for the United States: updated to 2020. White House Office of National AIDS Policy. Published July 2015. Accessed May 1, 2020. https://www.hiv.gov/federalresponse/national-hiv-aids-strategy/overview

12. Kay ES, Batey S and Mugavero MJ. The HIV treatment cascade and care continuum: updates, goals, and recommendations for the future. AIDS Res Ther (2016) 13:35.

13. Galárraga, O, Rana A, Rahman M et al. The effect of unstable housing on HIV treatment biomarkers: an instrumental variables approach. Soc Sci Med 2018; 214: 70-82.

14. Health Resources and Services Administration. Ryan White HIV/AIDS Program Annual Client-Level Data Report 2018. http://hab.hrsa.gov/data/data-reports. Published December 2019. Accessed May $1,2020$.

15. The U.S. Department of Housing and Urban Development, Office of Community Planning and Development. The 2018 Annual Homeless Assessment Report (AHAR) to Congress. Accessed May 11, 2020. https://files.hudexchange.info/resources/documents/2018-AHAR-Part-1.pdf

16. CDC HIV Prevention Progress Report, 2019. Downloaded on 12 May 2020 at:

https://www.cdc.gov/hiv/pdf/policies/progressreports/cdc-hiv-preventionprogressreport.pdf

17. Leaver C, Bargh G, Dunn JR, and Hwang SW. The effects of housing status on health-related outcomes in people living with HIV: a systematic review of the literature. AIDS and Behavior 2007; 11: 85-100.

18. Aidala AA, Wilson MG, Shubert V. et al. Housing status, medical care, and health outcomes among people living with HIV/AIDS: a systematic review. Am J Public Health 2016; 106: e1-e23.

19. Milloy M-J, Marshall BDL, Montaner J, and Wood E. Housing status and the health of people living with HIV/AIDS. Curr HIV/AIDS Rep 2012. 9 (4): 364-374.

20. Craig T. Homeless deaths surge. The Washington Post, April 13, 2018. 
21. Griffin A, Dempsey A, Cousino W et al. Addressing disparities in the health of persons with HIV attributable to unstable housing in the United States: the role of the Ryan White HIV/AIDS Program. PLoS Medicine 2020. 17 (3): 1-7.

22. Muthulingam $D$, Chin $J$, Hsu $L$ et al. Disparities in engagement in care and viral suppression among persons with HIV. J Acquir Immune Defic Syndr 2013. 63; 112-19.

23. Thakarar K, Morgan JR, Gaeta JM et al. Homelessness, HIV, and incomplete viral suppression. J Health Care Poor Underserved 2016. February; 27 (1): 145-156.

24. Loh J, Kennedy MC, Wood E et al. Longer duration of homelessness is associated with a lower likelihood of non-detectable plasma HIV-1 RNA viral load among people who use illicit drugs in a Canadian setting. AIDS Care 2016. 28 (11): 1448-54.

25. Clemenzi-Allen A, Geng E, Christopoulos K et al. Degree of housing instability shows independent "dose-response" with virologic suppression rates among people living with human immunodeficiency virus. Open Forum Infectious Diseases 2018; 1-3

26. Kidder DP, Wolitski RJ, Campsmith ML et al. Health status, health care use, medication use, and medication adherence among homeless and housed people living with HIV/AIDS. Am J Public Health 2007. Vol 97. No 12; 2238-45.

27. Bowen EA, Canfield J, Moore S et al. Predictors of CD4 health and viral suppression outcomes for formerly homeless people living with HIV/AIDS in scattered site supportive housing. AIDS Care 2017. Vol 29; Issue 11; 1458-62

28. Nasrullah M, Frazier EL, Fagan $\mathrm{J}$ et al. The association of recent incarceration and health outcomes among HIV-infected adults receiving care in the United States. Int J Prison Health 2016.12 (3): 135144.

29. Lim S, Nash D, Hollod L et al. Influence of jail incarceration and homelessness patterns on engagement in HIV care and HIV viral suppression among New York City adults living with HIV/AIDS. PLOS ONE November 23, 2015; 1-12.

30. Adams L, Nicholas T. Work and opportunity before and after incarceration. The Brookings Institution, March 2018.

31. Schwarcz SK, Hsu LC, Vittinghoff, et al. Impact of housing on the survival of persons with AIDS. BMC Public Health 2009. 9; 200: 1-18.

32. Lim S, Harris TG, Nash D, Lennon MC, and Thorpe LE. All-cause, drug-related, and HIV-related mortality risk by trajectories of jail incarceration and homelessness among adults in New York City. Am J Epidemiol 2015; 181 (4); 261-70

33. Hessol $\mathrm{Na}$, Eng M, Vu A et al. A longitudinal study assessing differences in causes of death among housed and homeless people diagnosed with HIV in San Francisco. BMC Public Health 2019. 19: 1440; 1-12.

34. Henry M, Mahathey A, Morrill T et al. The 2018 Annual Homeless Assessment Report (AHAR) to Congress. Part 1: Point-in-Time Estimates of Homelessness, December 2018. U.S. Department of Housing and Urban Development. Accessed May 4, 2020. 
https://www.hudexchange.info/resource/5783/2018-ahar-part-1pit-estimates-of-homelessness-inthe-us/

35. Nashville COVID-19 Task Force, Chair press briefing, May 4, 2020. Nashville Health Department.

36. Mosites E, Parker EM, Clarke KEN et al. Assessment of SARS-Cov-2 infection prevalence in homeless shelters-Four U.S. cities, March 27-April 15, 2020. MMWR Morb Mortal Wkly Rep. 2020

37. NYC Bureau of Communicable Disease Surveillance System preliminary report as of April 6, 2020. Accessed April 26, 2020. https://www1.nyc.gov/assets/doh/downloads/pdf/imm/covid-19-deathsrace-ethnicity-04082020-1.pdf

38. Garg S, Kim L, Whitaker M, et al. Hospitalization rates and characteristics of patients hospitalized with laboratory-confirmed coronavirus disease 2019-COVID-NET, 14 United States, March 1-30, 2020. MMWR Morb Mortal Wkly Rep. 2020: 69(15):458-464.

39. Michigan Department Health and Human Services April 2020. Accessed April 26, 2020. https://www.metrotimes.com/news-hits/archives/2020/04/02/black-people-make-up-12-ofmichigans-population-and-at-least-40-of-its-coronavirus-deaths

40. Culhane D, Treglia D, Steif K, et al. Estimated emergency and observational/quarantine capacity need for the US homeless population related to COVID-19 exposure by county; projected hospitalizations, intensive care units and mortality. Accessed May 12, 2020. https://works.bepress.com/dennis_cullhane/237/

41. Nashville Metro Public Health Department. Accessed May 4, 2020. https://www.tn.gov/health/cedep/ncov.html

42. Chetty R, Friedman JN, Hendren N, Stepner M, and the Opportunity Insights Team. Real-time economics: a new platform to track the impacts of COVID-19 on people, businesses, and communities using private sector data. May 2020. Accessed May 19, 2020. https://opportunityinsights.org/wp-content/uploads/2020/05/tracker_paper.pdf

43. Bhunu CP. Assessing the impact of homelessness on HIV/AIDS transmission dynamics. Cogent Mathematics 2015. 2:2-13

44. Weiser SD, Frongillo EA, Ragland $\mathrm{K}$ et al. Food insecurity is associated with incomplete HIV RNA suppression among homeless and marginally housed HIV-infected individuals in San Francisco. I Gen Intern Med 2008; 14-20

45. Riley ED, Neilands TB, Moore K et al. Social, structural and behavioral determinants of overall health status in a cohort of homeless and unstably housed HIV-infected men. PLoS ONE 2012; Vol 7; Issue 4; 1-7.

46. Craig T. Homeless deaths surge. Washington Post, April 13, 2018

\section{Figures}




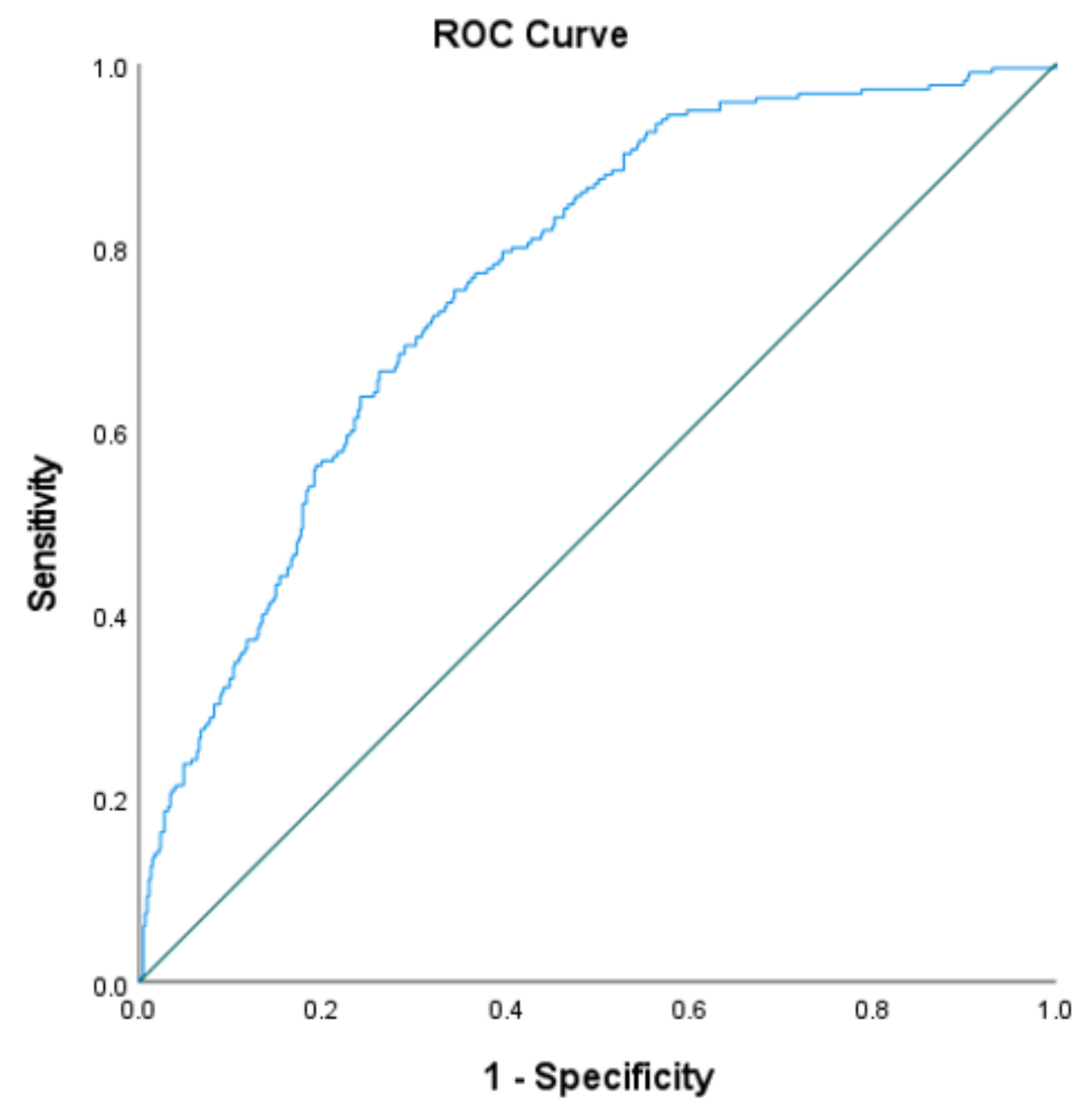

Figure 1

The CD 4 count cut-off of 500 cells $/ \mathrm{mm} 3$ was indeed representative of our patient population since $88.2 \%$ of them had CD 4 count greater than 200 cells $/ \mathrm{mm} 3$. Under the nonparametric assumption, the receiver operating characteristic (ROC) curve plotted in figure 1 correctly predicted $72.3 \%$ of the primary outcome variable, plasma HIV viral load suppression (AUC = 0.767; p-value < $0.001 ; 95 \% \mathrm{Cl}$ for $\operatorname{AUC}(0.73,0.80)$. During the five-year study period, 52 patients died. Of them, 16 (30.76\%) were homeless and $36(69.23 \%)$ lived in stable housing, while $12.5 \%$ of the homeless and $61.12 \%$ of those in stable housing achieved viral suppression at the time of death. 


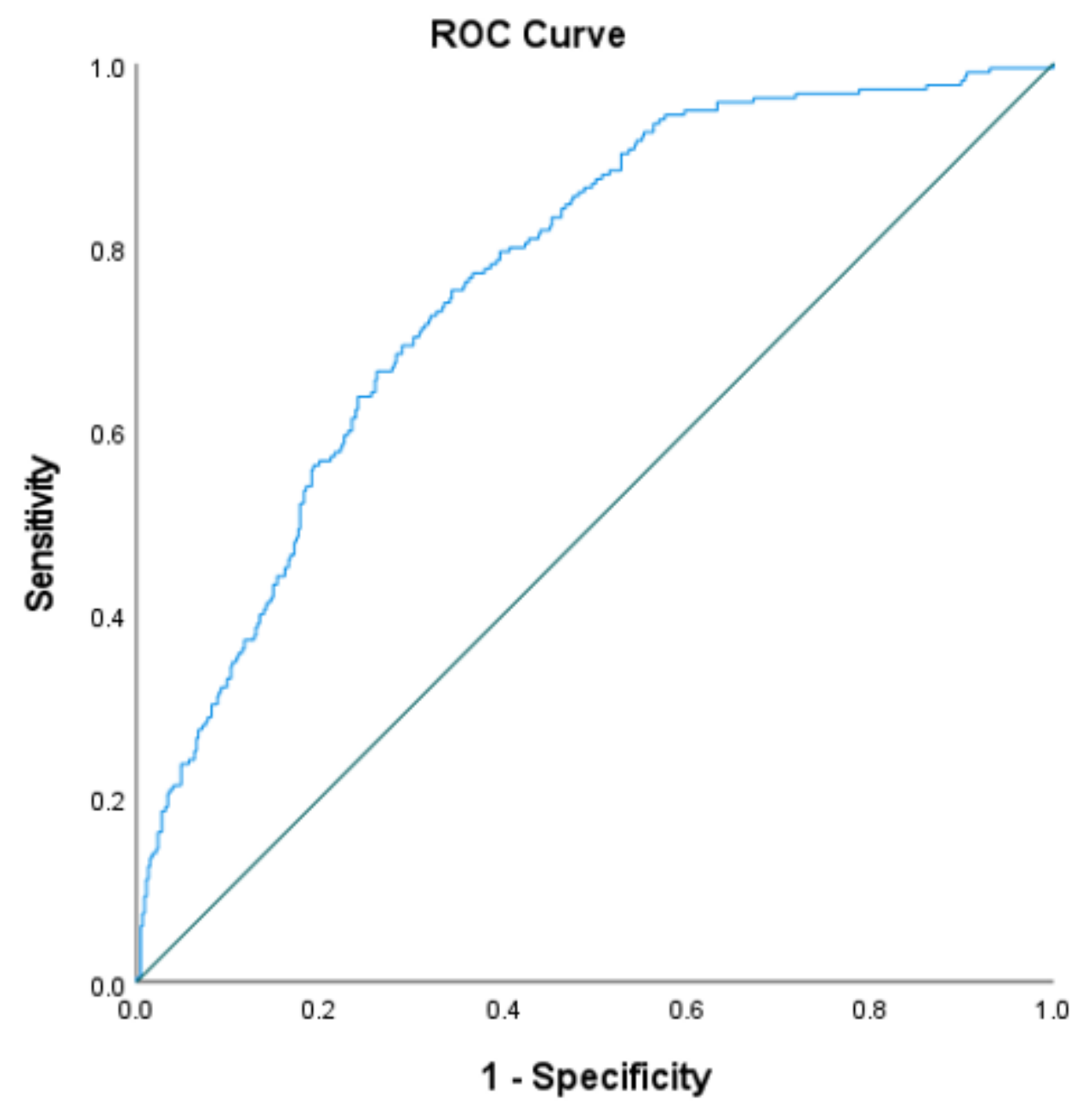

Figure 1

The CD 4 count cut-off of 500 cells $/ \mathrm{mm} 3$ was indeed representative of our patient population since $88.2 \%$ of them had CD 4 count greater than 200 cells $/ \mathrm{mm} 3$. Under the nonparametric assumption, the receiver operating characteristic (ROC) curve plotted in figure 1 correctly predicted $72.3 \%$ of the primary outcome variable, plasma HIV viral load suppression (AUC = 0.767; p-value < $0.001 ; 95 \% \mathrm{Cl}$ for $\operatorname{AUC}(0.73,0.80)$. During the five-year study period, 52 patients died. Of them, 16 (30.76\%) were homeless and $36(69.23 \%)$ lived in stable housing, while $12.5 \%$ of the homeless and $61.12 \%$ of those in stable housing achieved viral suppression at the time of death. 